\title{
How to Manage the Virtual Brand Community to Improve Brand Preference: Views from the Perceived Interactivity
}

\author{
Junxuan Zhu \\ University of International \\ Business and Economics \\ angelazjx@126.com
}

\author{
Ying Zhu \\ University of International \\ Business and Economics \\ zhuying0306@126.com
}

\author{
Ying Hua \\ University of International \\ Business and Economics \\ huaying@uibe.edu.cn
}

\begin{abstract}
The aim of this research is to investigate the effects of perceived interactivity of virtual brand community on customer perceived value as well as on brand preference. Data collected through a survey with 221 respondents supported the research model. This study classifies perceived interactivity as either with community or with customer, and posited that these two types have different operating mechanisms toward perceived value including emotional value, information value and social value, and brand preference. However perceived interactivity with customer does not affect brand preference significantly. Adapted by $S-O-R$ model, perceived value mediates the relationship between the degree of interactions on sites and brand preference. These two supplements on theoretical models clearly explain the source path of brand preference.
\end{abstract}

\section{Introduction}

With the growing trend of economic globalization, competition among brands has become increasingly intensified. The influence of the brand not only brings economic benefits, the brand will also form the value of a belief. In the fierce market competition, the product variety is abundant, but the homogeneity of the product is increasingly becoming a problem that the business operators and managers have to consider. For two similar products, whether they have formed a brand preference will often affect the consumers' intention and increase consumers' purchase behavior. Under this circumstance, research on brand preference, which is an important part of brand value, has important research value.

With the development of internet, people prefer to use social media such as online forums and instant

This study was funded in part by a grant from the National Key R\&D Program of China (2017YFB1400700). messaging tools to conduct communication. This kind of interaction without the limitation of time and space has formed a virtual assembly based on hobbies or special needs, that is, a virtual community. Some companies have built up their virtual brand communities in order to better communicate with customers, strengthen customer relationship management, and bring greater influence.

With the emergence of more and more virtual brand communities, various kinds of interactivity are slowly being recognized. Interactivity of the virtual brand community is different from the traditional offline ones. It is based on the network and information technology as a medium, thus not limited by time and space. It makes the customers' network more interactive and more diverse, as it includes not only the interactions between customers and the brand community but also with other members of the community. Through various types of interactions, customers can obtain the information they need and gain social value. As defined by Thorson and Rodgers $(2006)^{[1}$ 1 $]$ perceived interactivity is a simulation of interpersonal interaction and sense they are in the presence.

The research focuses on: whether the interactivity of the virtual brand communities generates interactive value; how the perceived interactivity of brand community affects and transfers into brand preference, and how companies improve customer's preference for the brand by managing interactivity of online brand community.

There has been plenty of research focus on customer satisfaction, loyalty and usage intention, therefore investigate how interactivity affects brands (Lee et al., 2015 $5^{[2]}$; Yang and Lee, 2017; ${ }^{[3]}$ ). However there are very few studies on the relationships of interactivities and brand preference, which connect closely to brand value. Based on the virtual brand community environment, this paper explores the influence of perceived interactivity on brand preference. In this paper, the authors report a study that attempts to fill this gap by introducing perceived 
value as a mediator, to explain interactivity has an impact on brand preference. For this purpose, the study draws upon the $\mathrm{S}-\mathrm{O}-\mathrm{R}$ model from environmental psychology (Mehrabian and Russell, $1974)^{[4]}$, reflects a process of customers in community, where they are stimulated ( $\mathrm{S}$, stimulus) and affected in psychological feeling (O, organism), then are driven in their responses ( $\mathrm{R}$, response).

The authors attempt to make two contributions to the literature with this study. First, the influence of perceived interactivity (in two ways) on brand preference constructed in this paper can indicate the factors that influence the brand preference, and then provide reliable theoretical support and practical guidance for expanding the brand influence. Second, it provides practical significance to wisely operate virtual brand communities in order to bring about better interactivity effects and improve the competitiveness of enterprises.

\section{Literature review and theoretical background}

\subsection{Virtual brand community}

The earliest definition of a virtual brand community is that it is not based on the constraints of the geographical environment and is based on the interaction between customers who like or use the same brand (Muniz and O'Guinn, 2001) ${ }^{[5]}$, and groups composed of non-geographically related special contacts, Compared to the consumer community (Boorstin, 1973) ${ }^{[6]}$, customers pay attention to their relationship with the brand and their relationship with other customers. Some scholars defined it as an "online brand community" (Kozinets, $2002)^{[7]}$. They believe that members of the brand community are mainly in the network environment, forming a specific social relationship. Through online forums, personal homepages, blogs, etc., they exchange views and experience of brand usage. This kind of social relationship is formed by groups who discuss their views on the brand through long-term exchanges in the brand community, which in turn leads to deeper interactivities and community commitment (Kuo and Feng, 2013) ${ }^{[8]}$. This research defines the virtual brand community as a virtual platform initiated by the company, with a specific brand as the theme for brand lovers to communicate, a social network established by long-term continuous interaction on the platform.

\subsection{Perceived interactivity (S)}

Baker et al. $(1994)^{9}$ adapted the S-O-R model to the retail context and conceptualized stimuli as environmental cues. Zhang et al. (2014) ${ }^{10}$ adapted the model into social commerce. The main feature of using information technology as an exchange medium is interactivity. Although interaction is a two-way concept, scholars give more perspective to the customer during the interpretation of the interaction process, emphasizing the subjective perception of the interaction between the customer and the product service provider (Sheth, 1976) ${ }^{[11]}$. Interaction refers to the "quality" of interaction and has been mentioned many times in the research of information systems. Research shows that interactivity is of crucial importance to the success of communications, marketing, advertising, and business, and also verifies the impact of interactivity on user behavior (Animesh et al., 2011 ${ }^{[12]}$ ).

\subsubsection{Interactivity of virtual brand community.} The research on interactivity mainly defines the interactivity from the perspective of features, processes, and perceptions.

The characteristic perspective highlights the technical characteristics, encodes interactive features based on the content analysis method, and evaluates the interactivity of the website based on the type and quantity (Voorveld et al., 2011) ${ }^{[13]}$. But, with more features, interaction is not necessarily better (Sohn, $2011)^{[14]}$.

The perspective of process defines the interactivity based on communication process and refers to the extent to which multiple communicators interact with each other and with the media and information (Liu and Shrum, 2002) ${ }^{[15]}$.The process perspective focuses on examining the degree of interaction. With the higher number of interactions through website, the better interactivity. However, compared with the process that the website backstage can accurately record interactions, it is generally difficult for researchers to obtain data on the process, and it is difficult to define standards that measure the level of interactivity (Koolstra and Bobs, 2009) ${ }^{[16]}$.

Compared above definitions, the perceived perspective focuses on better interactive experience the user experiences when interacting with website, and is a psychological state obtained from the interactions. The use of perceived perspectives can be a good predictor of customers' attitudes and behaviors. For this reason, a large number of studies explore the effects of perceived interactivity on cognitive and behavioral response (Van Noort et al., $2012)^{[17]}$. Perceived interactivity measures customer's subjective experiences from a psychological perspective. An outstanding feature of it is that it is 
not only easy to measure but also predicts users' attitudes and behaviors. Therefore, this article explains the interactivity based on this perspective and defines the perceived interactivity as the psychological state experienced by customers visiting the virtual brand community created by the company through the network.

2.2.2 The concepts of perceived interactivity. Perceived interactivity is a multi-dimensional concept. Despite recent conceptual discussions of perceived interactivity, no universal definition of this concept exists For example, Gao et al.(2009) ${ }^{[18]}$ constructed six dimensions in the context of mobile communication, is mainly applicable to mobile ads. There are also scholars in the study of the website's perceived interactivity, according to the existence of the three interactive relations, conceptualize interactions between people and systems, between people and content, and between person-to-person (Mcmahan et al., 2009) ${ }^{[19]}$. In the process of interactions with the community, users will subjectively evaluate various factors and draw on the concept of self-efficacy. Furthermore, studies propose two dimensions of perceived interactivity, namely, internal self-efficacy and external system effectiveness (Newhagen et al., 1995) ${ }^{[20]}$.

This paper concludes two dimensions of perceived interactivity, perceived interactivity with community and perceived interactivity with customers. Perceived interactivity with community is the degree of feedback the customer has given to browse the brand community, and the degree to which they can obtain the information they need $(\mathrm{Hu}$ et al, 2016) ${ }^{[21]}$. It also includes the degree of communication and interaction with the online customer service personnel of the company and the extent to which they can respond effectively. This enables the high-end resources of the company to demonstrate their performance.

As a result, the perceived interactivity with virtual brand community is reflected in three aspects: active control, responsiveness, and personalization. Active control refers to the consumer's ability to control behaviors that occur in the brand community, such as content, timing, and order of communication. Responsiveness refers to the ability to respond to inquiries from consumers. Personalization refers to the extent to which customized information or services respond to customer needs. Customers can personalize designs to highlight their individuality or subscribe to interesting screens that are not of interest.

Perceived interactivity with customers refers to the psychological experience that the customer communicates with each other. It's mainly reflected in the correspondence, referring to the ability of the brand community to provide customers with a sense of connection with the outside world.

\subsection{Perceived value $(0)$}

Studies that have applied the S-O-R model to the marketing and eCommerce context reveal that environmental stimuli influence consumers' internal states $(\mathrm{O})$. One internal state refers to emotional and cognitive states of consumers, i.e. perceived value. Researches on (customer) perceived value has been relatively mature, and improving perceived value as one of the key factors for a company's success. Variations exist in concepts of customer perceived value.

2.3.1 Measures of perceived value. Some scholars believe that CPV is a comprehensive evaluation of the effectiveness of a product for the customer's perception of profit and cost (Zeithaml, 1988) ${ }^{[22]}$. Woodruff (1997) ${ }^{[23}$ believed that CPV is the consumer's assessment of product and using experience-aware preferences. Although there are differences in concepts, many studies use the tradeoffs between perceived benefits and perceived gains and losses as the connotation of CPV. Therefore, this study adopts this understanding, taking CPV as a trade-off between perceived gain and loss.

The dimensions of CPV are also divided into various divisions. Sheth et al. (1991) ${ }^{[24]}$ constructed a five-dimensional model of CPV, that is functional, social, emotional, cognitive, and contextual values. Rintamki (2006) ${ }^{[25]}$ divided it into three, emotional value, functional value, and social value. Besides, perceived value is a construct that has been related to use of information (Toften and Olsen, 2004) $)^{[26]}$ especially in big data era. This paper draws on extant researches to summarize the perceived value of virtual brand community into emotional value, information value and social value. Emotional value refers to the emotional effect in using the brand community, a psychological experience, such as pleasure, satisfaction, etc. Information value means that users perceive that they can use the brand community to obtain useful information. Social value means that customers feel that they can be accepted by other customers and make friends in the brand community.

2.3.2 Relations between perceived value and brand preference. The interaction between the enterprise and the consumer will bring a pleasurable experience to the consumer because of the timely and individualized response that the enterprise makes to 
the consumer, that is, the consumer perceives value. Keng and Ting's (2009) ${ }^{[27]}$ verified this relationship by empirical test on blog users, either interpersonal or machine interaction browse playfulness and aesthetic experiences, generate experiential value.

The existing literature on interactivity and user behavior mainly studied the interactive influence results from the perspective of direct mediating roles. However, there are few studies related virtual brand communities, and no scholars have studied the relationship between these three. This paper conducts perceived interactivity with 2 dimensions from different resources. This article also introduces the perspective of perceived value, and explores the relationship between the perceived interactivity of virtual brand community and brand preference.

\subsection{Brand Preference( $(R)$}

Consumers' internal states subsequently drive their intention or behavior toward brand community, here, reflected as brand preference. The competition and mutual threats between brands are in fact determined by the subjective influence of consumers. This article believes that brand preference refers to consumers' preference for a certain brand compared to other competing brands, which is an understanding of consumers' brand selection intention. Some studies analysed the factors of brand preference from the perspective of consumers' characteristics and external environment (Sääksjärvi and Samiee, $2011^{[28]}$ ). Also, applying social media can positively influence the relationship quality between customer and brand (Simon et al., 2016) ${ }^{[29]}$. Many studies focus on the perspective of interactivity and customer perceived value (CPV, or perceived value).

2.4.1 Perceived interactivity effect. Interactivity helps brands develop effective ways to generate interaction between consumers and brands; Lee et al. $(2014)^{[30]}$ demonstrate the above in their advertising research. There are numbers of studies on the effects of interactivity, which are mainly reflected in behavioral responses and emotional responses. The behavioral response refers to the purchase intention and participation behavior. The better the interaction between the user and the website, the more likely it is that the user will have a purchase intention, which in turn leads to the purchase behavior $\left(\mathrm{Wu}, 2006\right.$; $^{[31]}$ Song and Zinkhan, 2008 ${ }^{[32]}$ ). The reaction to emotions is mainly reflected in trust, attitude, loyalty, satisfaction, and so on. The analysis found that the perceived transmission, control, and response of the website positively affect satisfaction (Song and
Zinkhan, 2008) ${ }^{[32]}$. Kim et al. (2012) ${ }^{[33]}$ found that, perceived interactivity will positively influence user's trust and attitude towards the website, whether interpersonal interaction or customer-machine interaction.

2.4.2 Perceived value effect. Brand preference is the judgement of multiple factors. In general, companies will gain consumer preference for the brand as long as they meet consumer needs for all aspects. (Zeithaml, 1988) ${ }^{[22]}$. This judgment processes activates cognitive nodes to associate the brand with certain attributes and features (Keller, 1993) ${ }^{[34]}$. Consumers engage emotionally and develop positive feelings towards it through brand experience (Ebrahim et al., 2016) $^{[35]}$.

\section{Hypotheses and theoretical model}

\subsection{Interactivity and brand preference}

Message and comment in the virtual brand community provides a private or open, synchronous or asynchronous two-way communication channel. These support customers initiate or stop conversations with the brand at any time, providing conditions for improving the responsiveness of the company and active control of customers. In addition, the virtual brand community is an environment with a high level of presence and self-exposure, which gives users the feeling of real interpersonal interaction. Interactivity enhances the relationship between brands and consumers beyond price through the brand images generated by consumers' interaction with brands (Lury, 2004) ${ }^{[36]}$.

If companies make full use of various interactive tools in the brand community to provide consumers with timely and personalized responses that contributes to eliminate doubts or misunderstandings, understand the details of products or promotions, and create a mutual understanding atmosphere with consumers. Virtual brand community allows customers to initiate and close conversations at any time, allowing customers to control the interactive process and content, and provide them with timely and useful information feedback to improve the quality of customer relationships (Ou et al., 2014) ${ }^{[37]}$, so that customers feel good about the brand. Based on the aforementioned, it can be hypothesised that:

H1a. A positive relationship exists between perceived interactivity with community and brand preference.

H1b. A positive relationship exists between perceived interactivity with customer and brand preference. 


\subsection{Interactivity and perceived value}

From the perspective of interactive technology, technical factors such as controllability, degree of two-way communication, and degree of synchronization all affect CPV. First, online interactivity promotes user to generate hedonic value (Fiore and Jin, 2005) ${ }^{[38]}$, emotional pleasure from virtual brand community has a consistently positive effect on approach responses. Second, active control increases product value and information usefulness, and the bidirectional dimension increases information usefulness and hedonic value. Brand interactivity increases the extent to which people engage in information processing of brands (Lee et al., 2014) ${ }^{[30]}$. Third, from the user's perspective, customers interact with websites, online suppliers, and interactions within consumers simultaneously or separately. Florenthal and Shoham (2010) ${ }^{[39]}$ argued that perceived activity is conducted to people's preferences through human-related mode, communication among human and includes preferences to socialize with friends, other customers or communicate with brands. The human-human interaction thus produces great user values, positive attitudes, and satisfaction (Zhao and Lu, 2012) ${ }^{[40]}$.

H2a. A positive relationship exists between perceived interactivity with community and perceived value.

$\mathrm{H} 2 \mathrm{~b}$. A positive relationship exists between perceived interactivity with customers and perceived value.

\subsection{Perceived value and brand preference}

Oliver $(1980)^{[} 4^{4} \quad$ ] believes that customer satisfaction is the consumer's judgment on the characteristics of products and services, products and services themselves to meet their own needs. It is a kind of psychological response after the consumer's needs are satisfied. A high level of customer satisfaction can increase the customer's preference for the brand. CPV is an important factor affecting customer's purchase decision and producing brand preference (Liu et al., 2014) ${ }^{[42]}$. Furthermore, The interpersonal interactions in the virtual brand community and the resulting information and associated social values can affect one's shopping decisions and post-purchase behavior. When consumers realize that they can meet their social needs by participating in a certain brand of online discussion or sharing brand information, consumers will largely have a higher interest and emotional dependence on the brand. In addition, positive emotion is found to be a crucial enabler of the urge to instantly share information on cyber space (Wang et al., 2015) ${ }^{[43]}$. This finding provides evidence for our assumption that instant information sharing is more impulsive and emotional in nature in comparison to traditional information sharing (Zhao and Lu, 2012) [40].

H3. A positive relationship exists between perceived value and brand preference.

The research model tested in this study is shown in Figure 1.

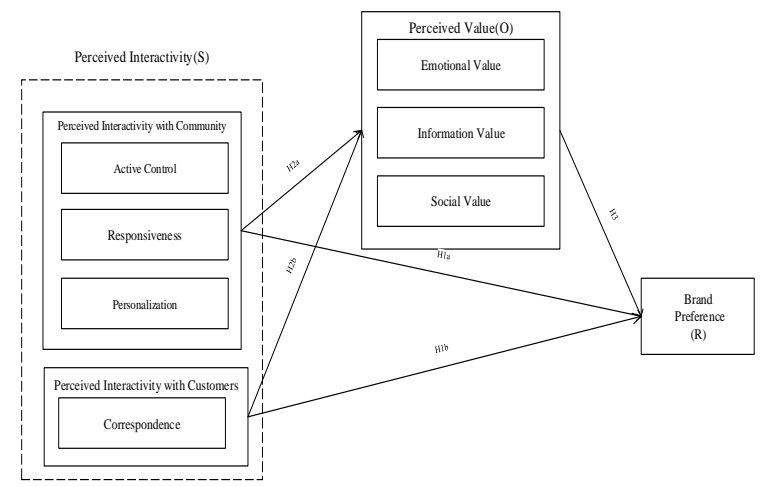

Figure 1. Theoretical model

\section{Research methodology}

An empirical survey is used to test the hypotheses. The sample is 207 users who browse virtual brand community frequently. All the questionnaire items used a five-point Likert-type scale, ranging from (1) strongly disagrees to (5) strongly agree. Data are analysed using structural equation modelling (SEM) to understand the cause and effect of the entire model and to determine the goodness of fit of the conceptual model.

\subsection{Sampling and data collection}

To ensure the rigor and scientific of the research, we conducted pre-test before formal investigation, and conducted exploratory factor analysis based on pre-test results to determine the final survey indicators. The sample for this study is collected through a web-based questionnaire survey in China. The questionnaire distributed in some virtual brand community websites. Respondents can fill out and submit by clicking on the invitation link to enter the survey page. A total of 221 questionnaires are received and among that, 207 are valid in more than two months. In the eventual questionnaire, men account for $41 \%$, women $59 \%$. $68 \%$ subjects are below 25 years old,26\% were $25-35$ years old and $5 \%$ are above 35 years old.54\% of the respondents have a bachelor degree, $39 \%$ have a master 
degree. $63 \%$ of the respondents are students, and $32 \%$ are salaried workers, $15 \%$ are run their own businesses.55\% of the respondents join the virtual brand community for more than 6 months. On average, respondents use virtual brand community about two or three times per week.

Table 1. Internal consistency of the constructs

\begin{tabular}{|c|c|c|c|c|c|}
\hline & Items & $\begin{array}{c}\text { Cronbach's } \\
\text { alpha }\end{array}$ & CR & AVE & $\begin{array}{l}\text { Factor } \\
\text { loading }\end{array}$ \\
\hline Active & & & & & 0.870 \\
\hline \multirow{2}{*}{ Control } & 3 & 0.814 & 0.890 & 0.729 & 0.887 \\
\hline & & & & & 0.802 \\
\hline \multirow{4}{*}{$\begin{array}{c}\text { Responsive } \\
\text {-ness }\end{array}$} & & & & & 0.832 \\
\hline & 4 & 0.801 & 0.870 & 0.629 & 0.879 \\
\hline & 4 & 0.001 & $0.0 / 0$ & 0.029 & 0.773 \\
\hline & & & & & 0.673 \\
\hline \multirow{3}{*}{$\begin{array}{l}\text { Personali- } \\
\text { zation }\end{array}$} & & & & & 0.870 \\
\hline & 3 & 0.724 & 0.837 & 0.632 & 0.766 \\
\hline & & & & & 0.743 \\
\hline \multirow{3}{*}{$\begin{array}{l}\text { Correspon- } \\
\text { dence }\end{array}$} & & & & & 0.791 \\
\hline & 3 & 0.788 & 0.876 & 0.703 & 0.845 \\
\hline & & & & & 0.876 \\
\hline \multirow{3}{*}{$\begin{array}{c}\text { Emotional } \\
\text { Value }\end{array}$} & & & & & 0.899 \\
\hline & 3 & 0.905 & 0.940 & 0.840 & 0.925 \\
\hline & & & & & 0.926 \\
\hline \multirow{4}{*}{$\begin{array}{l}\text { Information } \\
\text { Value }\end{array}$} & & & & & 0.857 \\
\hline & & & & & 0.852 \\
\hline & 4 & 0.866 & 0.909 & 0.714 & 0.869 \\
\hline & & & & & 0.8 \\
\hline Social & & & & & 0.847 \\
\hline \multirow[t]{2}{*}{ Value } & 3 & 0.844 & 0.906 & 0.763 & 0.905 \\
\hline & & & & & 0.867 \\
\hline \multirow{4}{*}{$\begin{array}{c}\text { Brand } \\
\text { Preference }\end{array}$} & & & & & 0.732 \\
\hline & 4 & 0787 & 0863 & 0612 & 0.798 \\
\hline & 4 & 0.181 & 0.863 & 0.012 & 0.753 \\
\hline & & & & & 0.841 \\
\hline
\end{tabular}

AVE: average variance extracted; CR: composition reality; SR: social relationships

\subsection{Instrument construction}

4.2.1 Perceived interactivity. The research applied previously developed scales, modified when necessary, to measure the variables. The Perceived interactivity of virtual brand community concludes two dimensions: perceived interactivity with community and perceived interactivity with customers. The role of Perceived interactivity of virtual brand community can be measured by active control, responsiveness, and personalization. Three items for active control $(\mathrm{Wu}, 2006)^{[31]}$, four items for responsiveness (de Ruyter and Wetzels, 2000) ${ }^{[44]}$; three items for personalization (Liu, 2003) ${ }^{[45]}$ were developed or adopted from previous studies. The role of Perceived interactivity of virtual brand customers can be measured by correspondence, which include three items (Wang and Fesenmaier, 2004 ${ }^{[46]}$; Cyra et al., 2009 $\left.{ }^{[47]}\right)$.

4.2.2 Perceived value. The role of Perceived interactivity of virtual brand community can be measured by emotional value, information value and social value. Three items for emotional value (Yoo et al., 2010) ${ }^{[48]}$, four items for information value and three items for social value (Nambisan and Baron, $2009)^{[49]}$ were developed from previous studies.

4.2.3 Brand preference. Four items for brand preference were developed from previous studies (Sirgy, 1997 ${ }^{[50]}$; Chen and Chang, 2008 ${ }^{[51]}$; Liu et al., $\left.2014^{[42]}\right)$.

\section{Result analysis}

\subsection{Data analysis}

In order to verify the hypotheses, this paper carried out required procedures for building a SEM and assuring model goodness of fit. The measurement and structural model are evaluated by the component-based partial least squares (PLS) approach with the Smart-PLS 3.0 software package.

This study assesses convergent validity using Cronbach's alpha, and composite construct reliability and average variance extracted (AVE). Discriminant validity was assessed by comparing the correlation of components to AVE. As seen in Table 1, the Cronbach's alpha mean for all concepts is above 0.8 , which are all higher than 0.6 , so in this respect this study has sufficient reliability. The study's AVE also satisfies the standard of 0.5 , AVE for all concepts are all higher than 0.6 , which means the measurement indexes satisfy the requirement for convergent validity.

The discriminant validity of constructs is assessed by comparing the square roots of the AVEs with other correlation scores in the correlation matrix. Table 2 shows none of the coefficient correlations (between 0.390 and 0.700 ) exceeded the square root of AVE (between 0.782 and 0.917). This suggests the measures of each construct correlated more highly with their own items than with items measuring other constructs. This ensures the discriminant validity of the constructs in the research model.

This is acceptable goodness of fit, which means that the methodology of this study is sufficiently reliable. The model accounts for 63.7 per cent of variance in Brand Preference and for 62.2 per cent of the variance in CPV. R-squared values above illustrate the mediating role as perceived value represents. 
As the data of constructs in this study are provided by the same subject and the questionnaire survey method is mainly used, this paper tests for common method bias to establish that it is not a likely factor in data collection. To do so, authors conduct Harman's single-factor test (Philip et al., $2003)^{[52]}$, the aim of the test is to see if a single extracted factor emerges or one factor that explains the majority of the variance in the model. The results of our factor analysis produce 27 distinct factors, the largest of which accounted for 44.33 percent of the variance of the model. We conclude that there is little reason to believe the data exhibit negative effects from common method bias.

Table 2. Analysis of discriminant validity

\begin{tabular}{lcccccccc}
\hline & $\mathbf{1}$ & $\mathbf{2}$ & $\mathbf{3}$ & $\mathbf{4}$ & $\mathbf{5}$ & $\mathbf{6}$ & $\mathbf{7}$ & $\mathbf{8}$ \\
\hline $\mathbf{1}$ & 0.854 & & & & & & & \\
$\mathbf{2}$ & 0.557 & 0.793 & & & & & & \\
$\mathbf{3}$ & 0.499 & 0.635 & 0.795 & & & & & \\
$\mathbf{4}$ & 0.566 & 0.483 & 0.657 & 0.838 & & & & \\
$\mathbf{5}$ & 0.498 & 0.411 & 0.586 & 0.700 & 0.917 & & & \\
$\mathbf{6}$ & 0.506 & 0.432 & 0.561 & 0.679 & 0.656 & 0.845 & & \\
$\mathbf{7}$ & 0.390 & 0.541 & 0.559 & 0.591 & 0.618 & 0.586 & 0.874 & 0.619 \\
$\mathbf{8}$ & 0.582 & 0.566 & 0.678 & 0.657 & 0.648 & 0.695 & 0.782 \\
\hline
\end{tabular}

Notes: $1-8$ stand for constructs

Table 3. Summary of hypothesis tests

\begin{tabular}{|c|c|c|c|}
\hline Hypothesis & SE & Coefficient & t-Statistic \\
\hline \multicolumn{4}{|l|}{ H1a: } \\
\hline $\begin{array}{l}\text { Perceived Interactivity } \\
\text { with Community }->\end{array}$ & .096 & 0.269 & $2.810 * *$ \\
\hline \multicolumn{4}{|l|}{ Brand Preference } \\
\hline \multicolumn{4}{|l|}{ H1b: } \\
\hline $\begin{array}{l}\text { Perceived Interactivity } \\
\text { with Customer }->\text { Brand } \\
\text { Preference }\end{array}$ & .081 & 0.120 & 1.489,NS \\
\hline \multicolumn{4}{|l|}{$\mathrm{H} 2 \mathrm{a}:$} \\
\hline $\begin{array}{l}\text { Perceived Interactivity } \\
\text { with Community -> }\end{array}$ & .073 & 0.234 & $3.190 * * *$ \\
\hline \multicolumn{4}{|l|}{ Perceive Value } \\
\hline \multicolumn{4}{|l|}{$\mathrm{H} 2 \mathrm{~b}$ : } \\
\hline $\begin{array}{l}\text { Perceived Interactivity } \\
\text { with Customer -> }\end{array}$ & .063 & 0.634 & $10.144 * * *$ \\
\hline \multicolumn{4}{|l|}{ Perceive Value } \\
\hline \multicolumn{4}{|l|}{ H3: } \\
\hline Perceive Value -> & .086 & 0.510 & $5.900 * * *$ \\
\hline \multicolumn{4}{|l|}{ Brand Preference } \\
\hline $\begin{array}{l}\text { SE: Standard Error; } \\
{ }_{* \star *} p<0.01\end{array}$ & S: & signi & ${ }^{* \star} p<0.05$ \\
\hline
\end{tabular}

PLS structural model results are shown in Figure 2 and summarized in Table 3.

This study concerns the direct impacts of perceived interactivity on brand preference through two dimensions (H1a and H1b). The relationship between perceived value with community and brand preference is less strongly supported as hypothesized in H1a $(\beta=0.269, \mathrm{p}<0.05)$. While the results suggest that perceived interactivity with customers does not affect brand preference as hypothesized in $\mathrm{H} 1 \mathrm{~b}$, at $\mathrm{p}<0.05$ or $\mathrm{p}<0.1$ level $(\beta=0.120)$.

This study hypothesises that 2 dimensions of perceived interactivity, will be positively associated with perceived value ( $\mathrm{H} 2 \mathrm{a}$ and $\mathrm{H} 2 \mathrm{~b})$. Indeed, the path coefficients for the 2 hypothesized associations are all positive and significant $(\beta=0.34, \mathrm{p}<0.01$ for $\mathrm{H} 2 \mathrm{a}$; $\beta=0.634, p<0.01$, for $\mathrm{H} 2 \mathrm{~b}$ ).

As shown in Figure 2, the effect of perceived value on brand preference is significant and positive $(\beta=0.510, \quad \mathrm{p}<0.01)$, supporting $\mathrm{H} 3$ is about the mediating role of perceived value between 2 dimensions of perceived interactivity and brand preference.

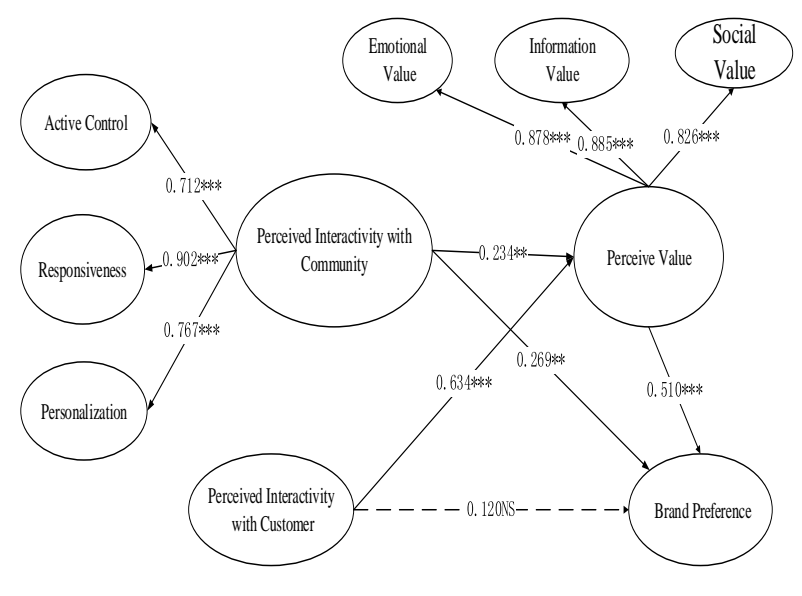

Note: ${ }^{* *} p<0.01,{ }^{* *} p<0.05$; NS: not significant

Figure 2. Results of suggested research model

\section{Discussion}

As organizations increasingly use virtual brand community for business purpose, in this study, the authors explore how perceived interactivity and 
perceived value could affect brand preference. This study creatively divides perceived interactivity from sources, and learns the path on how brand preference is acquired. All hypothesis are supported by conducting a survey of 207 samples, expect for the relationship between perceived interactivity with customers and brand preference.

This study finds that brand preference is more resulted in perceived interactivity with community than with customers. For a brand community that wants to gain direct brand preference, it does not make sense to just maintain interactions within customers. In fact, we often notice that the person in charge of a community or a section often participates in interactions with customers, including responding to customer queries and a series of pre-sales, in-sales and after-sales customer service. It advised more company-initiated activities as it is more important in enhancing customer commitment.

Perceived interactivity helps members of virtual brand community gain useful content that is the inherent psychological reward for their activities. In contrast with $\mathrm{H} 1 \mathrm{a}$ and $\mathrm{H} 1 \mathrm{~b}$, perceived interactivity with customers plays a more important role in CPV than perceived interactivity with community. This may be due to the fact that the unmanaged interactions between customers may be intuitive or even negative. Therefore, the interactions between customers will likely lead to service failure and affect customer evaluation and satisfaction with the brand. This result also leads to the consideration of management of customer relationships. If companies can identify, understand, and influence customer interactions to promote and encourage specific customer behaviors, then good customer relationship management can be implemented.

Members of brand community perceived information value, social and emotional value, and transfer into voluntary affection on brand. While perceived interactivity with community effects on brand preference either directly or indirectly through perceived value, perceived interactivity with customers effects on brand preference positively just in the help of perceived value. The reason for this positive relationship may be that the value perceived by the customer is often positive for the virtual brand community. This finding implies that, while creating an environment that triggers interactions between customers, it is important to let customers perceive the value.

\section{Conclusion and limitations}

\subsection{Conclusion of findings}

This article extends the literature of virtual brand community. First, previous works mostly concentrate on motivations of interactivity and how it turns into satisfaction and continuous intention of use. This study focuses on virtual brand community, and visualizes the customer's middle and later movements to brand preference. It reports a study at the intersection of perceived interactivity, perceived value and brand preference, examining the impact of perceived interactivity on virtual brand community, and impact of perceived interactivity on brand preference through the perceived value.

Second, recognizing the crucial roles of community and customers in determining perceived interactivity, authors concentrate on two constructs, namely perceived interactivity with community and customers. This study suggests that perceived interactivity with virtual brand community and customers helps to grow customer perceived value on brand, which facilitates customer generating affections on brand and subsequently leads to brand preference.

Third, this study extends the applicability of the $\mathrm{S}-\mathrm{O}-\mathrm{R}$ model to virtual brand community. Drawing on this model, this study offers a validated model, that direct impact of interactivity on brand preference is relatively weak. It is noteworthy that interactions between customers can not lead to brand preference.

Some additional implications for virtual brand community leaders can be derived from the study's findings. First, community should concentrate on both perceived interactivity and perceived values, although the direct role of perceived interactivity is weak but it also serves as the main factor of emotional value, information value and social value. Second, pay more attention on interactions within customers as brand preference is partially affected or even not significantly influenced by such perceived interactivity with customers. Finally, based on the present finding that perceived values have a significant positive impact on brand preference, companies should continuously filter out high-value materials from their site in order to make the community more useful for customers.

\subsection{Limitations and future directions}

This study investigated the usage of virtual brand community considering virtual brand community tools in general, without dividing them into different industries and functions. Future studies could concentrate on virtual brand communities of various features, which might provide a more complete understanding of the impact of that particular tool on brand building and maintenance. 
In addition, as noted above, 14 questionnaires were deleted due to too many missing values, and before data processing, 80 questionnaires were dropped due to infrequent use of viral brand community. The dropped cases may lead to a selection bias, such that the results may not be generalizable to the entire population.

\section{References}

${ }^{[1]}$ K.S. Thorson and S. Rodgers, "Relationships between Blogs as eWom and Interactivity, Perceived Interactivity, and Parasocial Interaction", Journal of Interactive Advertising, Taylor \& Francis, Abingdon, March 2006, pp. $5-44$.

${ }^{[2]}$ D. Lee, J. Moon, Y.J. Kim et al., "Antecedents and Consequences of Mobile Phone Usability: Linking Simplicity and Interactivity to Satisfaction, Trust, and Brand Loyalty", Information \& Management, Elsevier, Amsterdam, April 2015, pp. 295-304.

[ 3 ] S. Yang and Y.J. Lee, "The Dimensions of MInteractivity and Their Impacts in the Mobile Commerce Context", International Journal of Electronic Commerce, Routledge, Abingdon, 2017, pp. 548-571.

[4] A. Mehrabian and J.A. Russell, An Approach to Environmental Psychology, The MIT Press, Cambridge, 1974.

${ }^{[5]}$ A.M. Muniz, Jr. and T.C. O'Guinn, "Brand Community", Journal of Consumer Research, Oxford Univ Press, Oxford, March 2001, pp. 412-432.

[ 6 ] D.J. Boorstin, The Americans: The Democratic Experience, Random House, New York, 1973.

[7] R.V. Kozinets, "The Field Behind the Screen: Using Netnography for Marketing Research in Online Communities," Journal of Marketing Research, American Marketing Association, Chicago, February 2002, pp. 61-72.

${ }^{[8]}$ Y.F. Kuo, L.H. Feng, "Relationships among Community Interaction Haracteristics, Perceived Benefits, Community Commitment, and Oppositional Brand Loyalty in Online Brand Communities", International Journal of Information Management, Elsevier, Kidlington, December 2013, pp. 948-962.

[9] J. Baker, D. Grewal and A. Parasuraman, "The Influence of Store Environment on Quality Inferences and Store Image", Journal of the Academy of Marketing Science, Springer, New York, September 1994, pp. 328-339.

[ 10] H. Zhang et al., "What Motivates Customers to Participate in Social Commerce? The Impact of Technological Environments and Virtual Customer Experiences", Information \& Management, Elesvier, Amsterdam, December 2014, pp. 1017-1030.

[11] J.N. Sheth, "Buyer-seller interaction: a conceptual framework", Advances in Consumer Research, Association for Consumer Research, Duluth, January 1976, pp. 382-386.

[12] A. Animesh, A. Pinsonneault, and S.B. Yang, "An Odyssey into Virtual Worlds: Exploring the Impacts of Technological and Spatial Environments on Intention to Purchase Virtual Products”, MIS Quarterly, Management
Information Systems Research Center, Minneapolis, September 2011, pp.789-810.

${ }^{[13]}$ H.A.M. Voorveld, P.C. Neijens and E.G. Smit, "The Relation Between Actual And Perceived Interactivity: What Makes the Web Sites of Top Global Brands Truly Interactive?", Journal of Advertising, Taylor \& Francis, Abingdon, Summer 2011, pp.77-92.

[ 14 ] D. Sohn, "Anatomy of Interaction Experience: Distinguishing Sensory Semantic, and Behavioral Dimensions of Interactivity", New Media \& Society, Sage, London, December 2011, pp. 1320-1335.

${ }^{[15]}$ Y. Liu and L.J. Shrum, "What Is Interactivity and Is It Always Such a Good Thing? Implications of Definition, Person, and Situation for the Influence of Interactivity on Advertising Effectiveness", Journal of Advertising, Taylor \& Francis, Abingdon, December 2002, pp. 53-64.

${ }^{[16]}$ C. M. Koolstra and M.J.W. Bos, "The Development of an Instrument to Determine Different Levels of Interactivity", International Communication Gazette, Sage, London, 6 July, 2009, pp. 373-391.

${ }^{[17]}$ G. Van Noort, H. Voorveld and E.A. Van Reijmersdal, "Interactivity in Brand Web Sites: Cognitive, Affective, and Behavioral Responses Explained by Consumers' Online Flow Experience", Journal of Interactive Marketing, Elsevier, New York, November 2012, pp.223-234.

[18] Q. Gao, P.L.P. Rau and G. Salvendy, "Measuring Perceived Interactivity of Mobile Advertisements", Behaviour \& Information Technology, Taylor \& Francis, Abingdon, Jan-Feb 2010, pp. 35-44.

${ }^{[19]}$ C. McMahan, R. Hovland and S. McMillan, "Online Marketing Communications: Exploring Online Consumer Behavior by Examining Gender Differences and Interactivity within Internet Advertising", Journal of Interactive Advertising, Elsevier, New York, September 2009, pp. 61-76.

${ }^{[20]}$ J.E. Newhagen, J.W. Cordes and M.R. Levy, "Audience Scope and the Perception of Interactivity in Viewer Mail on the Internet", Journal of Communication, Oxford University Press, Cary, September 1995, pp.164-175.

[21] M. Hu, M. Zhang and N. Luo, "Understanding Participation on Video Sharing Communities: The Role of Self-Construal and Community Interactivity", Computers in Human Behavior, Elsevier Kidlington, September 2016, pp.105-115.

[22 ] V.A. Zeithaml, "Consumer Perceptions of Price, Quality, and Value: A Means-End Model and Synthesis of Evidence", Journal of Marketing, American Marketing Association, Birmingham, July 1988, pp.2-22.

${ }^{[23]}$ R.B. Woodruff, "Customer Value: The Next Source of Competitive Advantage", Journal of the Academy of Marketing Science, Springer, New York, March 1997, p. 139.

${ }^{[24]}$ J.N. Sheth, B.I. Newman, and B.I. Gross, Consumption Values and Market Choice, South Western Publishing, Nashville, 1991.

${ }^{[25]}$ T. Rintamäki, "Decomposing the Value of Department Store Shopping into Utilitarian, Hedonic and Social Dimensions: Evidence from Finland", International Journal of Retail \& Distribution Management, Emerald, Bingley, January 2006, pp. 6-24. 
${ }^{[26]}$ K. Toften and S.O. Olsen, "The Relationships Among Quality, Cost, Value, and Use of Export Market Information: An Empirical Study", Journal of International Marketing, AMA, Chicago, Summer 2004, pp. 104-131.

${ }^{[27]}$ C.J. Keng and H.Y. Ting, "The Acceptance of Blogs: Using a Customer Experiential Value Perspective", Internet Research, Emerald, Bingley, 2009, pp. 479-495.

${ }^{[28]}$ M. Sääksjärvi and S. Samiee, "Relationships among Brand Identity, Brand Image and Brand Preference: Differences between Cyber and Extension Retail Brands over Time", Journal of Interactive Marketing, Elsevier, Amsterdam, August 2011, pp. 169-177.

${ }^{[29]}$ S. Hudson, L. Huang, M. S. Roth et al., "The influence of social media interactions on consumer-brand relationships: a three-country study of brand perceptions and marketing behaviors", International Journal of Research in Marketing, Elsevier, Amsterdam, March 2016, pp. 27-41.

[30] J. Lee, H. Park and K. Wise, "Brand Interactivity and Its Effects on the Outcomes of Advergame Play", New Media \& Society, Sage, London, December 2014, pp. $1268-1286$.

${ }^{[31]} \mathrm{G}$. $\mathrm{Wu}$ "Conceptualizing and Measuring the Perceived Interactivity of Websites", Journal of Current Issues \& Research in Advertising, Taylor \& Francis, Abingdon, Spring 2006, pp. 87-104.

[32] J.H. Song and G.M. Zinkhan, "Determinants of Perceived Web Site Interactivity", Journal of Marketing, American Marketing Association, Chicago, March 2008, pp. $99-113$.

${ }^{[33]}$ J. Kim, N. Spielmann and S.J. Mcmillan, "Experience Effects on Interactivity: Functions, Processes, and Perceptions", Journal of Business Research, Elsevier, New York, November 2012, pp. 1543-1550.

[ 34 ] K.L. Keller, "Conceptualizing, Measuring, and Managing Customer-Based Brand Equity", Journal of Marketing, American Marketing Association, Chicago, January 1993, pp. 1-22.

${ }^{[35]}$ R. Ebrahim, A. Ghoneim and Z. Iran et al., "A Brand Preference and Repurchase Intention Model: The Role of Consumer Experience”, Journal of Marketing Management, Taylor \& Francis, Abingdon, 09 May 2016, pp. 1230-1259.

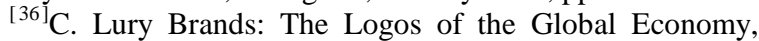
Routledge, New York, 2004.

${ }^{[37]}$ Ou, P.A. Pavlou "Swift Guanxi in Online Marketplaces: The Role of Computer-Mediated Communication Technologies", MIS Quarterly, Management Information Systems Research Center, Minneapolis, March 2014, pp. 09-230.

${ }^{[38]}$ A.M. Fiore and H.J. Jin, "For Fun and Profit: Hedonic Value from Image Interactivity and Responses toward an Online Store", Wiley, Hoboken, August 2005, pp. 669-694.

[39] B. Florenthal and A. Shoham, "Four-Mode Channel Interactivity Concept And Channel Preferences", Journal Of Services Marketing, Emerald, Yorkshire, 2010, pp. 2941.

${ }^{[40]}$ L. Zhao and Y. Lu, "Enhancing Perceived Interactivity through Network Externalities: An Empirical Study on Micro-Blogging Service Satisfaction and Continuance
Intention", Decision Support Systems, Elsevier, Amsterdam, November 2012, pp. 825-834.

[41] R.L. Oliver, "A Cognitive Model of the Antecedents and Consequences of Satisfaction Decisions", Journal of Marketing Research, American Marketing Association, Birmingham, November 1980, pp. 460-469.

[42] M.T. Liu, I. Wong, G. Shi et al., "The Impact of Corporate Social Responsibility (CSR) Performance and Perceived Brand Quality on Customer-Based Brand Preference", Journal of Services Marketing, Emerald, Bingley 2014, pp. 181-194.

[43] C. Wang, X.L. Jin, Z. Zhou, Z. et al., "Effect of Perceived Media Capability on Status Updates in Microblogs", Electronic Commerce Research and Applications, Elsevier, Amsterdam, May-June 2015, pp. 181-191.

[44] K. de Ruyter and M.G.M. Wetzels, "The Impact of Perceived Listening Behavior in Voice-to-Voice Service Encounters", Journal of Service Research, Sage, London, 1 February 2000, pp. 276-284.

[ 45 ] Y. Liu, "Developing a Scale to Measure the Interactivity of Websites", Journal of Advertising Research", Cambridge University Press, Cambridge, June 2003, pp. 207-216.

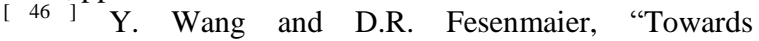
Understanding Members, General Participation in and Active Contribution to an Online Travel Community", Tourism Management, Elsevier, Amsterdam, December 2004, pp.709-722.

[47] D. Cyra, M. Headb and A. Ivanovc, "Perceived Interactivity Leading to E-Loyalty: Development of A Model for Cognitive Affective User Responses", International Journal of Human Computer Studies, Elsevier, Amsterdam, October 2009, pp. 850-869.

[48] W.S. Yoo, Y. Lee and J.K. Park "The Role of Interactivity in E-Tailing: Creating Value and Increasing Satisfaction", Journal of Retailing \& Consumer Services, Elsevier, Amsterdam, March 2010, pp.89-96.

[49] S. Nambisan and R.A. Baron, "Virtual Customer Environments: Testing a Model of Voluntary Participation in Value Co - creation Activities", Journal of Product Innovation Management, Wiley, Hoboken, 4 May 2010, pp. 388-406.

[ 50 ] M.J. Sirgy, D. Grewal, T.F. Mangleburg et al., "Assessing the Predictive Validity of Two Methods of Measuring Self-Image Congruence", Journal of the Academy of Marketing Science, Springer, New York, June 1997, pp. 229-241.

[51] C.F. Chen and Y.Y. Chang, "Airline Brand Equity, Brand Preference, and Purchase Intentions-The Moderating Effects of Switching Cost", Journal of Air Transport Management, Elsevier, Amsterdam, June 2008, pp. 40-42.

[52] P.M. Podsakoff et al., "Common Method Biases in Behavioral Research: A Critical Review of the Literature and Recommended Remedies", Journal of Applied Psychology, Taylor \& Francis, November 2003, pp. 879903. 